\title{
Mineralogical controls on Arsenic Stability in the Poldice Mine, Cornwall
}

\author{
JULIAN TANG ${ }^{1}$, ERIC OELKERS ${ }^{2}$, JULIEN DECLERCQ ${ }^{3}$, \\ ROB BOWELL ${ }^{4}$ \\ ${ }^{1}$ SRK Consulting, 17 Churchill Way, Cardiff, CF10 2HH, \\ UK, jtang@srk.co.uk \\ ${ }^{2}$ University College London, Gower Street, London, WC1E \\ 6BT, UK, e.oelkers@ucl.ac.uk \\ ${ }^{3}$ SRK Consulting, 17 Churchill Way, Cardiff, CF10 2HH, \\ UK, jdeclercq@srk.co.uk \\ ${ }^{4}$ SRK Consulting, 17 Churchill Way, Cardiff, CF10 2HH, \\ UK, rbowell@srk.co.uk
}

Exposure of humans to drinking water with high arsenic content can lead to health issues including: hyperpigmentation keratosis (including skin cancers), liver fibrosis and many others. Mining in Cornwall for copper and tin took place at least by the early eighteenth century. This project aims to explore the effectiveness of previous land remediating practices at the Poldice Mine in Cornwall, United Kingdom, to prevent the spread of toxic metals such as arsenic (As) in streams and groundwater. Site $\mathrm{pH}$ regimes vary from 2.5 to circum-neutral. Water, rocks and soils from its mine tailings dam and along the Carnon River were analysed using Inductively Coupled Plasma - optical emission spectrometry (ICP-OES) and Inductively Coupled Plasma - mass spectrometry (ICP-MS) to determine the concentration of individual elements in each samples. Dissolved As reaches up to $1 \mathrm{mg} / \mathrm{L}$ in places, and exceeds the current WHO drinking water guideline of $0.01 \mathrm{mg} / \mathrm{L}$ by 100 times. Examination of potential remediating strategies were performed by modelling using PHREEQC, altering the $\mathrm{pH}$ and electric potential (pe) of the water separately. The data shows a mixing zone of water from the mine tailings and the underground adit into the Carnon River which joins the Fal Estuary and discharges into the English Channel. The Asbearing mineral, scorodite, was found to be controlling the concentration of As in the Carnon River; model output shows the saturation index to be close to equilibrium. Remediating strategies have been made in this study, by varying $\mathrm{pH}$ and pe at increments of $+/-1$ each time but did not give favourable results. This study further reviews previous literature of how findings from the Poldice Mine is applicable to other historic mine tailings site where a year-round wet climate takes place. 